\title{
Recent epidemiologic trends of diabetes mellitus among status Aboriginal adults
}

\author{
Richard T. Oster MSc, Jeffrey A. Johnson PhD, Brenda R. Hemmelgarn PhD MD, Malcolm King PhD, \\ Stephanie U. Balko MSc, Lawrence W. Svenson BSc, Lindsay Crowshoe MD, Ellen L. Toth MD
}

\begin{abstract}
Background: Little is known about longitudinal trends in diabetes mellitus among Aboriginal people in Canada. We compared the incidence and prevalence of diabetes, and its impact on mortality, among status Aboriginal adults and adults in the general population between 1995 and 2007.
\end{abstract}

Methods: We examined de-identified data from Alberta Health and Wellness administrative databases for status Aboriginal people (First Nations and Inuit people with treaty status) and members of the general public aged 20 years and older who received a diagnosis of diabetes mellitus from Apr. 1, 1995, to Mar. 31, 2007. We calculated the incidence and prevalence of diabetes and mortality rate ratios by sex and ethnicity in 2007. We examined the average relative changes per year for longitudinal trends.

Results: The average relative change per year in the prevalence of diabetes showed a smaller increase over time in the Aboriginal population than in the general population (2.39 v. $4.09, p<0.001)$. A similar finding was observed for the incidence of diabetes. In the Aboriginal population, we found that the increase in the average relative change per year was greater among men than among women (3.13 v. 1.88 for prevalence, $p<0.001 ; 2.60$ v. 0.02 for incidence, $p=0.001)$. Mortality among people with diabetes decreased over time to a similar extent in both populations. Among people without diabetes, mortality decreased in the general population but was unchanged in the Aboriginal population (-1.92 v. $0.11, p=0.04$ ). Overall, mortality was higher in the Aboriginal population than in the general population regardless of diabetes status.

Interpretation: The increases in the incidence and prevalence of diabetes over the study period appeared to be slower in the status Aboriginal population than in the general population in Alberta, although the overall rates were higher in the Aboriginal population. Mortality decreased among people with diabetes in both populations but was higher overall in the Aboriginal population regardless of diabetes status.
$\mathrm{T}$ he health of Aboriginal people in Cana$\mathrm{da}$ is generally poorer than their nonAboriginal counterparts, and diabetes mellitus is a significant contributor. ${ }^{1,2}$ Studies have shown that type 2 diabetes and its complications occur at rates two to five times higher in Canada's Aboriginal population than in the general population. ${ }^{3-7}$ In response, diverse diabetes programs have materialized, including various community-based prevention and screening projects. ${ }^{8-10}$ The federally funded Aboriginal Diabetes Initiative was created to emphasize health promotion and diabetes prevention. ${ }^{11}$ In addition, numerous Aboriginal communities have established their own diabetes and health programs. ${ }^{12}$

Accurate diabetes surveillance data are essential for governments and health care organizations to plan health care delivery and translate knowledge into policy and funding decisions.
However, research into the longitudinal trends of diabetes in Aboriginal populations is scarce. For the most part, data have come from small, community-based studies and self-reported surveys. Population-based studies of primary data are few and have been conducted only for limited periods. Even less is known about outcomes, mortality in particular, among Aboriginal individuals with diabetes.

The use of administrative data is becoming more common for tracking diabetes in Canada. ${ }^{13}$ The National Diabetes Surveillance System uses administrative health data to document the burden of the disease, but it has little information on Aboriginal people. Dyck and colleagues recently used the methodology of the National Diabetes Surveillance System to examine the incidence and prevalence of diabetes among Aboriginal people in the province of Saskatchewan, ${ }^{14}$ and
Competing interests: None declared.

This article has been peer reviewed.

Correspondence to:

Richard Oster,

roster@ualberta.ca

CMAJ 2011. DOI:10.1503

/cmaj.101882 
similar analyses were conducted in Manitoba and Ontario. . $^{15,16}$

As part of the Alberta Diabetes Surveillance System, we conducted this study to compare the incidence and prevalence of diabetes among people 20 years and older in the status Aboriginal population (First Nations and Inuit people with treaty status) and the general population in the province of Alberta between 1995 and 2007. We also compared trends in mortality in the two populations among people with and without diabetes.

\section{Methods}

\section{Study population}

We obtained de-identified data from Alberta Health and Wellness administrative databases (discharge abstract database, physician claims, ambulatory care classification system and vital statistics) for people living in the province of Alberta who were 20 years of age and older. Data on people less than 20 years of age will be reported elsewhere.

We identified people with a diagnosis of diabetes by applying the Alberta Diabetes Surveil- lance System algorithm, which requires that an individual with diagnosed diabetes have either two physician visits within two years or one hospital admission because of diabetes (ICD-9 [International Classification of Diseases, ninth revision], code 250 or ICD-10 codes E10-E14). ${ }^{17}$ This case definition is identical to that of the National Diabetes Surveillance System except that the national algorithm excludes pregnant women, who are assumed to have gestational diabetes. We included pregnant women in our study because of their elevated risk of subsequent type 2 diabetes. ${ }^{18}$ In addition, the Alberta fee-for-service data include up to three diagnostic codes, and all three are used for case identification. The methodology of the national surveillance system for identifying people with diabetes has been validated in non-Aboriginal populations $^{13,19}$ and in an Aboriginal community in Alberta. ${ }^{20}$

Status Aboriginal people were identified from the Alberta Health Care Insurance Plan registry and were defined as any resident in the province who was registered under the Indian Act of Can-

\begin{tabular}{|c|c|c|c|}
\hline Variable & $\begin{array}{l}\text { Status Aboriginal* } \\
\quad n=72725\end{array}$ & $\begin{array}{c}\text { General population* } \\
n=2433695\end{array}$ & $\begin{array}{l}\text { Rate ratio } \\
(95 \% \mathrm{Cl}) \dagger\end{array}$ \\
\hline \multicolumn{4}{|l|}{ Prevalence, no. (\%) } \\
\hline All & $7055(13.5)$ & $154213(6.0)$ & $2.25(2.23-2.27)$ \\
\hline Females & $4081(15.4)$ & 74271 & $2.66(2.63-2.68)$ \\
\hline Males & $2974(11.5)$ & $79942 \quad(6.2)$ & $1.85(1.84-1.87)$ \\
\hline Rate ratio $(95 \% \mathrm{Cl}) \neq$ & $1.34(1.31-1.37)$ & $0.94(0.93-0.94)$ & \\
\hline \multicolumn{4}{|c|}{ Incidence, no. (rate per 1000) } \\
\hline All & $547(11.1)$ & 14833 (6.5) & $1.72(1.69-1.75)$ \\
\hline Females & $295(11.9)$ & $6572 \quad(5.7)$ & $2.10(2.05-2.15)$ \\
\hline Males & $252(10.3)$ & $8261 \quad(7.3)$ & $1.41(1.38-1.44)$ \\
\hline Rate ratio $(95 \% \mathrm{Cl}) \ddagger$ & $1.16(1.06-1.26)$ & $0.78(0.77-0.79)$ & \\
\hline \multicolumn{4}{|c|}{ Mortality, no. (rate per 1000) } \\
\hline \multicolumn{4}{|l|}{ With diabetes } \\
\hline All & $146(17.2)$ & $4052(10.8)$ & $1.59(1.54-1.64)$ \\
\hline Females & 78 (17.9) & $1805(10.6)$ & $1.69(1.64-1.74)$ \\
\hline Males & $68(16.5)$ & $2247(11.0)$ & $1.50(1.44-1.56)$ \\
\hline Rate ratio $(95 \% \mathrm{Cl}) \neq$ & $1.08(0.90-1.26)$ & $0.96(0.93-0.99)$ & \\
\hline \multicolumn{4}{|l|}{ Without diabetes } \\
\hline All & $500(14.3)$ & 14482 (6.5) & $2.21(2.18-2.25)$ \\
\hline Females & $185(12.0)$ & $7086 \quad(6.2)$ & $1.93(1.89-1.98)$ \\
\hline Males & $315(16.6)$ & $7396 \quad(6.7)$ & $2.47(2.42-2.53)$ \\
\hline Rate ratio $(95 \% \mathrm{Cl}) \ddagger$ & $0.72(0.66-0.78)$ & $0.92(0.90-0.93)$ & \\
\hline \multicolumn{4}{|c|}{$\begin{array}{l}\text { Note: } \mathrm{Cl}=\text { confidence interval. } \\
\text { *Rates were standardized by age and by age and sex to the } 2001 \text { Alberta Census population in five-year bands. } \\
\text { tRate ratio of Aboriginal to general population. } \\
\text { †Rate ratio of females to males. }\end{array}$} \\
\hline
\end{tabular}


ada and entitled to treaty status with the federal government during the study period. An individual with a status Aboriginal identifier (First Nations or Inuit) was classified as "status Aboriginal." We included individuals living on or off reserve. Nonregistered Aboriginal people, including Métis individuals, were included in the general population comparison group. Although the Métis constitute a sizeable group of perhaps $2 \%-3 \%$ of the Alberta population, these individuals are self-identifying and can have varied genetic and cultural Aboriginal connections. Nonregistered First Nations individuals are smaller in number.

\section{Outcome measures}

We calculated the prevalence and incidence of diabetes, as well as mortality among people with and without diabetes, among status Aboriginal adults and adults in the general population from Apr. 1, 1995, to Mar. 31, 2007. When calculating the prevalence of diabetes, we determined the proportion of status Aboriginal people who had diabetes and compared it with the proportion of the general population with diabetes at the same point. The first year in which an individual met the criteria for diabetes (with no diabetes claims in the preceding two years) was considered an incident year; the person was considered to have prevalent diabetes in subsequent years.

\section{Statistical analysis}

Prevalence, incidence and mortality data were age- and sex-standardized to the 2001 Alberta population (from Canadian census data) by means of the direct method. ${ }^{21}$ Age- and sexstandardized rate ratios and $95 \%$ confidence intervals (CIs) were calculated for the two study populations in 2007.

We computed the average annual per cent change (hereafter referred to as the average relative change per year) in prevalence, incidence and mortality from 1995 to 2007 for crude and standardized values using the Joinpoint Regression Program (version 3.4.2; Statistical Research and Applications Branch, US National Cancer Institute, Rockville, Md.). The average relative change per year provides a summary measure of the trend over a prespecified fixed interval. An average relative change per year with a $p$ value of less than 0.05 was considered to be a statistically significant change over time. Tests of parallelism were then performed to determine whether the trend over time for the status Aboriginal and general populations differed. If the $p$ value was less than 0.05 for the test of parallelism, the trend over time was considered to be statistically significantly different between groups. Age-adjusted analyses were also performed according to sex.

\section{Results}

As of 2007 and according to Alberta Health and Wellness administrative databases, 2506420 adults were living in Alberta, 72725 of whom were status Aboriginal individuals. Also in 2007, there were 161268 people with prevalent diabetes, 7055 of whom were status Aboriginal individuals. Throughout the study period, the prevalence and incidence of diabetes were higher in the status Aboriginal population than in the general population. Mortality was also higher in the status Aboriginal population than in the general population, both among people with diabetes and among those without diabetes. Table 1 shows the prevalence, incidence and mortality data for the most recent year of the study.

Table 2: Average relative change per year in the prevalence and incidence of diabetes mellitus and in mortality among people aged 20 years or more in Alberta, 1995-2007*

\begin{tabular}{|c|c|c|c|}
\hline \multirow[b]{2}{*}{ Variable } & \multicolumn{3}{|c|}{ Average relative change per year $(95 \% \mathrm{Cl}), \%$} \\
\hline & Status Aboriginal & General population & $\begin{array}{l}p \text { value for } \\
\text { difference } \neq\end{array}$ \\
\hline \multicolumn{4}{|l|}{ Prevalence } \\
\hline All & 2.39 (2.32 to 2.46$)$ & 4.09 (3.94 to 4.22$)$ & $<0.001$ \\
\hline Females & 1.88 (1.77 to 1.99$)$ & 3.82 (3.68 to 3.97$)$ & $<0.001$ \\
\hline Males & 3.13 (3.00 to 3.27$)$ & 4.36 (4.20 to 4.51$)$ & 0.005 \\
\hline $\begin{array}{l}p \text { value for } \\
\text { difference } \dagger\end{array}$ & $<0.001$ & 0.001 & \\
\hline \multicolumn{4}{|l|}{ Incidence } \\
\hline All & $1.21 \quad(0.25$ to 2.17$)$ & 4.55 (3.68 to 5.42$)$ & 0.53 \\
\hline Females & $0.02(-1.31$ to 1.36$)$ & 4.47 (3.73 to 5.23$)$ & 0.02 \\
\hline Males & 2.60 (1.02 to 4.18$)$ & 4.60 (3.54 to 5.68$)$ & 0.22 \\
\hline $\begin{array}{l}p \text { value for } \\
\text { differencet }\end{array}$ & 0.01 & 0.38 & \\
\hline \multicolumn{4}{|l|}{ Mortality } \\
\hline \multicolumn{4}{|c|}{ With diabetes } \\
\hline All & $-2.12(-5.00$ to -0.84$)$ & $-2.80(-3.25$ to -2.35$)$ & 0.62 \\
\hline Females & $-1.97(-5.06$ to 1.22$)$ & $-2.46(-2.86$ to -2.06$)$ & 0.73 \\
\hline Males & $-2.52(-6.52$ to 1.66$)$ & $-3.15(-4.07$ to -2.27$)$ & 0.08 \\
\hline $\begin{array}{l}p \text { value for } \\
\text { differencet }\end{array}$ & 0.79 & 0.17 & \\
\hline \multicolumn{4}{|c|}{ Without diabetes } \\
\hline All & 0.11 (-0.63 to 0.86$)$ & $-1.92(-2.10$ to -1.74$)$ & 0.04 \\
\hline Females & $-0.16(-1.01$ to 0.70$)$ & $-1.55(-1.79$ to -1.30$)$ & 0.76 \\
\hline Males & 0.44 (-0.97 to 1.87$)$ & $-2.25(-2.48$ to -2.02$)$ & 0.003 \\
\hline $\begin{array}{l}p \text { value for } \\
\text { differencet }\end{array}$ & 0.63 & $<0.001$ & \\
\hline \multicolumn{4}{|c|}{$\begin{array}{l}\text { Note: } \mathrm{Cl}=\text { confidence interval. } \\
\text { *Rates were standardized by age and by age and sex to the } 2001 \text { Alberta Census population in five- } \\
\text { year bands. } \\
\text { +Between males and females. } \\
\text { †Between status Aboriginal population and general population. }\end{array}$} \\
\hline
\end{tabular}


Between 1995 and 2007, increases in the prevalence and incidence of diabetes were observed in both study groups (Table 2, Figures 1 and 2). The rise in age- and sex-adjusted prevalence in the status Aboriginal population was less than that in the general population (Table 2). Similarly, the incidence of diabetes increased over time in the status Aboriginal population, but to a lesser extent compared with the increase in the general population (Table 2). Increases in incidence among men did not differ significantly between the two populations (Table 2). Among women, the incidence increased at a much lower rate in the status Aboriginal population than in the general population (Table 2). In the status Aboriginal population, both the incidence and prevalence of diabetes increased more among men than among women (Table 2). Men in the general population also experienced greater increases in prevalence than women did, but trends in the incidence of diabetes were similar between the sexes (Table 2).

Mortality among individuals with diabetes decreased over time in both populations, with no significant differences between the groups (Table 2, Figure 2). Among individuals without diabetes, mortality was unchanged in the status Aboriginal population and decreased in the general population (Table 2). The annual relative change per year in mortality showed a greater decrease among men in the general population without diabetes than that among their female counterparts (Table 2).

\section{Interpretation}

Our results describe several trends in diabetes among status Aboriginal adults in the province of Alberta. Increases in the prevalence and incidence of diabetes from 1995 to 2007 were less pronounced in the Aboriginal population than in the general population. Aboriginal men experienced an accelerated rise in prevalence and incidence compared with their female counterparts; thus, the sex-specific gap in diabetes among Aboriginal adults diminished over the study period. Mortality was higher in the Aboriginal population than in the general population re-
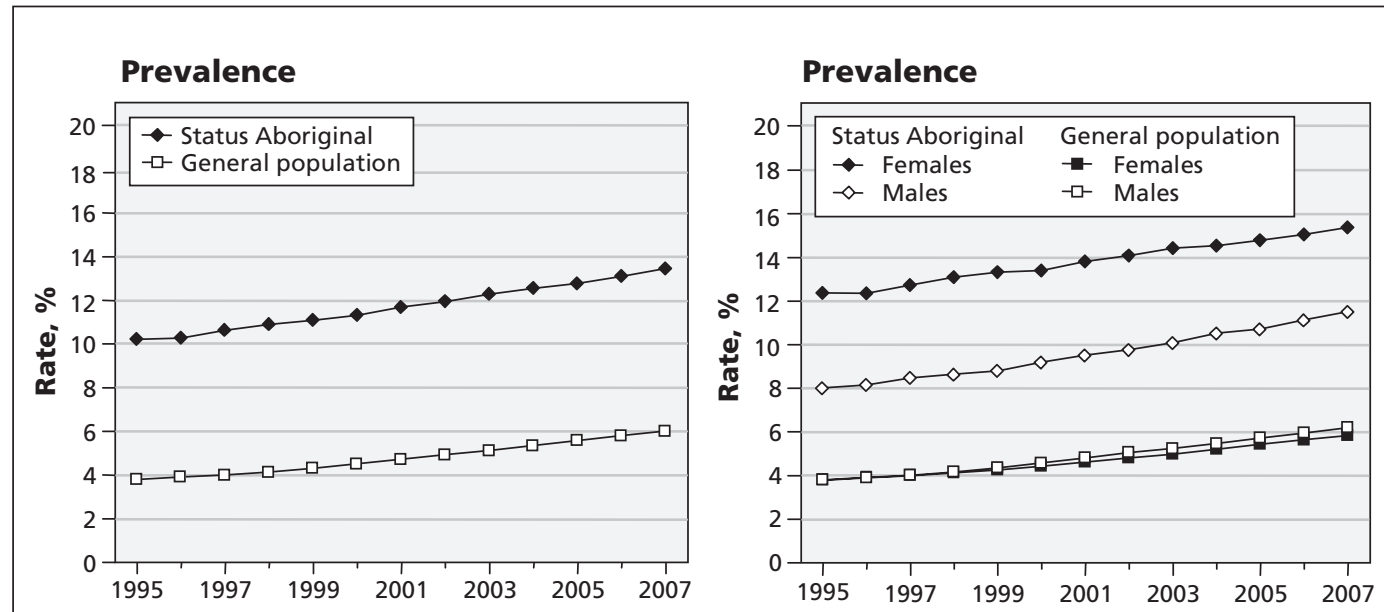

Incidence
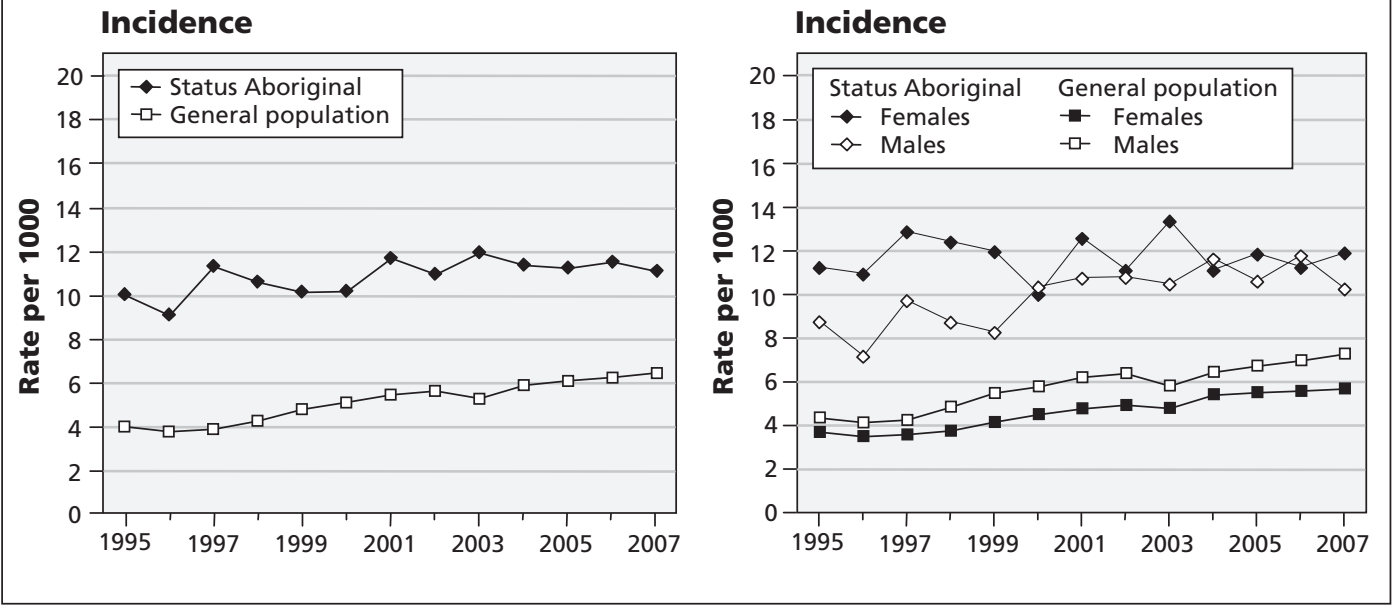

Figure 1: Prevalence and incidence of diabetes mellitus among people aged 20 years or more in Alberta, from Apr. 1, 1995, to Mar. 31, 2007, by ethnicity and sex. Rates were standardized by age and by age and sex to the 2001 Alberta Census population in five-year bands. 
gardless of diabetes status. A growing divergence in mortality between the Aboriginal population and the general population among individuals without diabetes was observed.

The magnitude of the differences in the incidence and prevalence of diabetes between the status Aboriginal adults and adults in the general population in Alberta appears to be less than in other provinces where these rates have been described, namely Saskatchewan, Manitoba and Ontario. ${ }^{14-16}$ For example, status Aboriginal-togeneral population rate ratios of the prevalence of diabetes in Saskatchewan were 3.7 among women and 2.6 among men in $2005,{ }^{14}$ as compared with 2.7 among women and 1.9 among men in 2007 in our study. Our data also challenge previous epidemiologic reports that suggested that prevalence rates among Aboriginal people will continue to rise unabated ${ }^{3,7,14-16}$ and that rates among Aboriginal women markedly outweigh those among men. ${ }^{14,22}$

Provincial differences cannot be explained by our study, but we speculate that they may be related to socioeconomic differences, or they

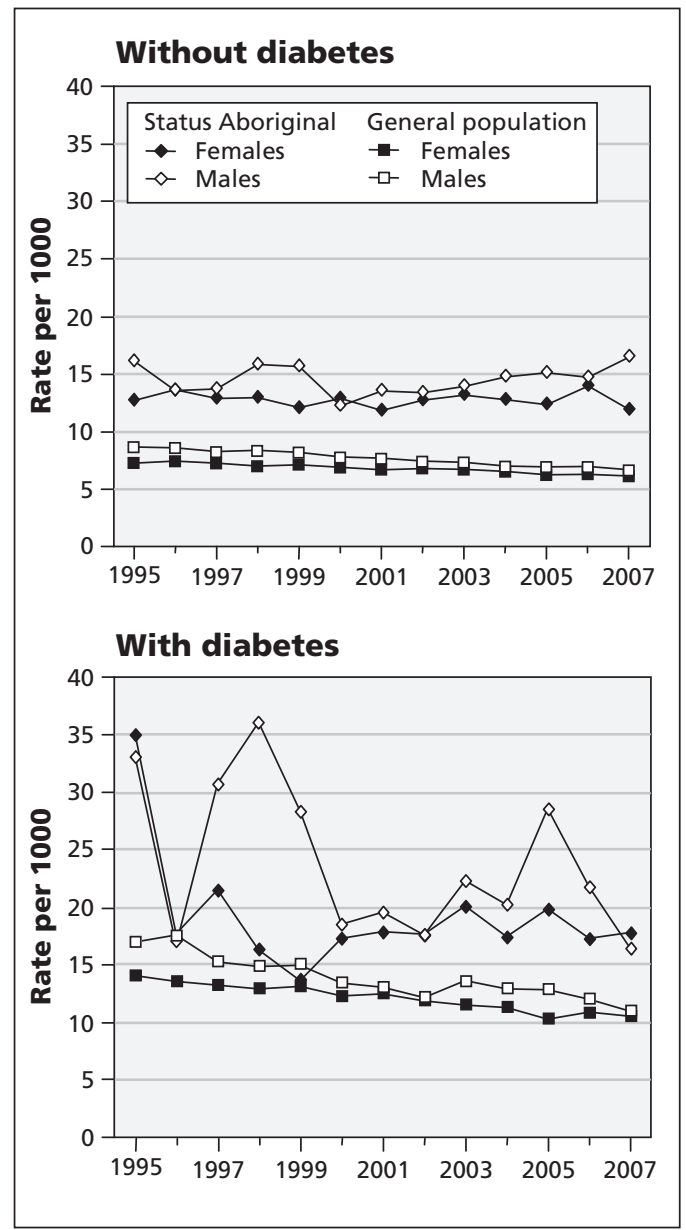

Figure 2: Age-adjusted mortality among people aged 20 years or more in Alberta, from Apr. 1, 1995, to Mar. 31, 2007, by ethnicity and sex. may be related to combined provincial and community-based programs that increase awareness of diabetes (e.g., the provincial Alberta Diabetes Strategy), to federally funded activities (e.g., the Aboriginal Diabetes Initiative) or to changes in clinical practice with increased emphasis on screening. ${ }^{23,24}$

The decreases in mortality observed among status Aboriginal adults with diabetes over the study period are consistent with findings from a recent study of ours showing improved diabetesrelated health among status Aboriginal adults in Alberta. ${ }^{10}$ The growing divergence in mortality observed between status Aboriginals and the general population without diabetes is sadly in contrast to national trends from 1980 to 2001, which showed an improvement in life expectancy among registered Indians, from 60.9 to 70.4 years among men and from 68.0 to 75.5 years among women..$^{25}$

\section{Limitations}

The prevalence and incidence rates of diabetes derived from the administrative health data may be underestimated in the Aboriginal population owing to the lack of data on undiagnosed diabetes. Undiagnosed diabetes is common in Aboriginal communities, ${ }^{4}$ possibly because of discomfort with Western medical environments ${ }^{26}$ or a lack of physicians in remote communities. ${ }^{27}$ In contrast, our inclusion of pregnant women with possible gestational diabetes in the definition criteria for diabetes may have inflated the rates in the status Aboriginal population, because gestational diabetes has been shown to be more common among Aboriginal women than among non-Aboriginal women..$^{28}$ We were unable to distinguish between type 1 and type 2 diabetes in the administrative data. Our results cannot be generalized to the Métis and nonregistered Aboriginal people in Alberta, who could not be identified and were subsequently included in the general population group. Lastly, modifications to the Indian Act in 1985 through Bill C-3129 may be leading to increases in the status Aboriginal population, and equally some descendants of status Aboriginal people are losing their status through the "three generations" rule. ${ }^{30}$ Taken together, caution is needed when interpreting the observed epidemiologic results among status Aboriginals.

\section{Conclusion}

Increases in the incidence and prevalence of diabetes over the study period appeared to be slower in the status Aboriginal population than in the general population in Alberta, although the overall rates were higher in the Aboriginal population. Mortality decreased among people with 
diabetes in both populations but was higher overall in the Aboriginal population regardless of diabetes status. Reasons for the prevalence rates of diabetes among status Aboriginal adults being lower in Alberta than in other provinces need to be explored. Also, the lack of improvement in mortality over the 12-year study period among status Aboriginal adults without diabetes necessitates further investigation.

\section{References}

1. Adelson N. The embodiment of inequity: health disparities in Aboriginal Canada. Can J Public Health 2005;96(Suppl 2):S45-61

2. Gracey M, King M. Indigenous health part 1: determinants and disease patterns. Lancet 2009;374:65-75.

3. Young TK, Reading J, Elias B, et al. Type 2 diabetes mellitus in Canada's First Nations: status of an epidemic in progress. CMAJ 2000;163:561-6.

4. Harris SB, Gittelsohn J, Hanley A, et al. The prevalence of NIDDM and associated risk factors in Native Canadians. Diabetes Care 1997;20:185-7.

5. Dean HJ, Young TK, Flett B, et al. Screening for type-2 diabetes in Aboriginal children in northern Canada. Lancet 1998;352: 1523-4.

6. Kaler SN. The BRAID study: believing we can reduce the Aboriginal incidence of diabetes [dissertation]. Edmonton (AB) University of Alberta; 2005.

7. Dannenbaum D, Kuzmina E, Lejeune P, et al. Prevalence of diabetes and diabetes-related complications in First Nations communities in northern Quebec (Eeyou Istchee), Canada. Can J Diabetes 2008:32:46.

8. Hanley AJ, Harris SB, Mamakeesick M, et al. Complications of type 2 diabetes among Aboriginal Canadians: prevalence and associated risk factors. Diabetes Care 2005;28:2054-7.

9. Daniel M, Green LW, Marion SA, et al. Effectiveness of community-directed diabetes prevention and control in a rural Aboriginal population in British Columbia, Canada. Soc Sci Med 1999; 48:815-32.

10. Oster RT, Shade S, Strong D, et al. Improvements in indicators of diabetes-related health status among First Nations individuals enrolled in a community-driven diabetes complications mobile screening program in Alberta, Canada. Can J Public Health 2010; 101:410-4.

11. Diabetes among Aboriginal people in Canada: the evidence. Ottawa (ON): Aboriginal Diabetes Initiative; 2000.

12. Public Health Agency of Canada. Building a national diabetes strategy: a strategic framework. Ottawa (ON): The Agency; 2005.

13. Chen G, Khan N, Walker R, et al. Validating ICD coding algorithms for diabetes mellitus from administrative data. Diabetes Res Clin Pract 2010;89:189-95.

14. Dyck R, Osgood N, Lin TH, et al. Epidemiology of diabetes mellitus among First Nations and non-First Nations adults. CMAJ 2010;182:249-56.

15. Green C, Blanchard JF, Young TK, et al. The epidemiology of diabetes in the Manitoba-registered First Nation population: current patterns and comparative trends. Diabetes Care 2003;26:1993-8.

16. Shah BR, Anand S, Zinman B, et al. Diabetes and First Nations people. In: Hux JE, Booth GL, Slaughter PM, et al., editors. Diabetes in Ontario: an ICES practice atlas. Toronto $(\mathrm{ON})$ : Institute for Clinical Evaluative Sciences; 2003.

17. National Diabetes Surveillance System. Report from the National Diabetes Surveillance System: diabetes in Canada, 2008. Ottawa (ON): Public Health Agency of Canada; 2008. Available: www.ndss.gc.ca (accessed 2010 Nov. 16).

18. Kim C, Newton KM, Knopp RH. Gestational diabetes and the incidence of type 2 diabetes: a systematic review. Diabetes Care 2002;25:1862-8.

19. Hux JE, Ivis F, Flintoft V, et al. Diabetes in Ontario: determination of prevalence and incidence using a validated administrative data algorithm. Diabetes Care 2002;25:512-6.

20. Oster RT, Ralph-Campbell K, Toth EL. Type 2 diabetes in Aboriginal peoples in Alberta: validation of the national algorithm for identifying incident and prevalent adults with type 2 diabetes. Edmonton (AB): Braid Research; 2008. Available: www.braiddm.ca/validation.html (accessed 2010 Nov. 20).

21. Age (122) and sex (3) for population, for Canada, provinces, territories, census divisions, census subdivisions and dissemination areas, 2001 census - 100\% data. Ottawa (ON): Statistics Canada; 2002. Cat. no. 95F0300XCB2001001. Available: www.statcan gc.ca/bsolc/olc-cel/olc-cel?catno=95F0300XCB2001001\&lang =eng (accessed 2010 Nov. 10).

22. First Nations Centre, National Aboriginal Health Organization. First Nations Regional Longitudinal Health Survey (RHS) 2002/03: results for adults, youth and children living in First Nations communities. Ottawa (ON): First Nations Centre, National Aboriginal Health Organization; 2005. Available: www.rhs-ers.ca/sites/default/files/ENpdf/RHS 2002/rhs2002-03 -technical_report.pdf (accessed 2011 June 24).

23. Canadian Diabetes Association. Canadian Diabetes Association 2003 clinical practice guidelines for the prevention and management of diabetes in Canada. Can J Diabetes 2003;27(Suppl 2): S1-S152.

24. Canadian Diabetes Association. Canadian Diabetes Association 2008 clinical practice guidelines for the prevention and management of diabetes in Canada. Can J Diabetes 2008;32(Suppl 1):S1-S201.

25. Basic departmental data 2004. Ottawa (ON): Indian and Northern Affairs Canada; 2004.

26. King M, Smith A, Gracey M. Indigenous health part 2: the underlying causes of the health gap. Lancet 2009;374:76-85.

27. Lu DJ, Hakes J, Bai M, et al. Rural intentions: factors affecting the career choices of family medicine graduates. Can Fam Physician 2008;54:1016-7.

28. Dyck R, Klomp H, Tan LK, et al. A comparison of rates, risk factors, and outcomes of gestational diabetes between Aboriginal and non-Aboriginal women in the Saskatoon health district. Diabetes Care 2002;25:487-93.

29. Furi M, Wherrett J. Indian status and band membership issues. Ottawa (ON): Library of Parliament; 1996, revised 2003. Publication no. BP-410E.

30. Indian and Northern Affairs Canada. Registered Indian demography: population, household and family projections, 2004 2029. Ottawa (ON): Indian and Northern Affairs Canada; 2004.

Affiliations: From the Departments of Medicine (Oster, King, Toth) and Public Health Sciences (Johnson, Svenson), University of Alberta, Edmonton, Alta.; the Departments of Medicine, (Hemmelgarn) and Family Medicine (Crowshoe), University of Calgary, Calgary, Alta.; the Institute of Health Economics (Balko), Alberta Diabetes Surveillance System, Edmonton, Alta.; Surveillance and Environmental Health (Svenson), Alberta Health and Wellness, Edmonton, Alta.; and the Department of Medicine (Toth), Walter C. MacKenzie Hospital, Edmonton, Alta.

Contributors: Richard Oster contributed to the analysis and interpretation of the data and drafted the manuscript. Jeff Johnson was responsible for data analysis and integrity and contributed to manuscript revisions. Brenda Hemmelgarn, Malcolm King, Stephanie Balko, Lawrence Svenson and Lindsay Crowshoe contributed to the interpretation of the data and to manuscript revisions. Ellen Toth contributed to the analysis and interpretation of the data and to manuscript revisions. All of the authors approved the final version of the manuscript submitted for publication.

Funding: This work was supported in part by a Team Grant to the Alliance for Canadian Health Outcomes Research in Diabetes (grant no. OTG-88588), sponsored by the Canadian Institutes for Health Research Institute of Nutrition, Metabolism and Diabetes. Funding for the Alberta Diabetes Surveillance System comes from Alberta Health and Wellness.

Acknowledgements: The authors thank Sheri Pohar for her contributions to the data analysis.

This study is based in part on de-identified data provided by Alberta Health and Wellness. The interpretation and conclusions contained herein do not necessarily represent those of the Government of Alberta or Alberta Health and Wellness. 